\title{
The European Union provides funding to strengthen the protection against zoonoses and animal diseases
}

Eurosurveillance editorial team (eurosurveillance@ecdc.europa.eu) ${ }^{1}$

1. European Centre for Disease Prevention and Control (ECDC), Stockholm, Sweden

Eurosurveillance editorial team. The European Union provides funding to strengthen the protection against zoonoses and animal diseases.

Euro Surveill. 2011;16(46):pii=20019. Available online: http://www.eurosurveillance.org/ViewArticle.aspx?Articleld=20019

Article published on 17 November 2011

On 9 November 2011, the European Union (EU) adopted measures to support programmes across the EU aimed at monitoring, controlling and eradicating zoonoses and animal diseases. A EUR 203 million envelope has been earmarked to support annual and multi-annual programmes aimed at assisting Member States in fighting animal diseases that affect human and animal health.

The money will go to programmes aimed at reducing, among other diseases, salmonellosis, rabies and transmissible spongiform encephalopathies (TSE's), as well as avian influenza, bovine tuberculosis, bluetongue, brucellosis and classical swine fever.

The notification rate of salmonellosis in humans has decreased steadily over the past five years but it is still the second most commonly reported zoonosis and eradication programmes will need support for the foreseeable future. Some EUR 16 million will be set aside to assist Member States in the fight against salmonellosis.

The rabies situation in the EU is improving but Member States will receive continued financial support to help them with the fight to eradicate rabies and to increase public health protection. The Member States provide their own funding and the programmes to combat rabies are therefore co-funded by themselves and the EU. Vaccination programmes in the areas of Belarus, Ukraine and Russia will be funded to reduce the risk of introduction of rabies from these countries into the EU.

As the incidence of TSE's continues to fall, largely due to strict risk management measures, monitoring requirements for bovines have been relaxed. Member States will receive EUR 54 million from the EU budget to ensure continued support against TSE's.

Member States will also continue to carry out surveillance for avian influenza in poultry and wild birds in 2012 with the financial assistance of $€ 2.3$ million from the EU budget. The implementation of the surveillance programmes is the most effective way to detect early outbreaks and is extremely useful in preventing the spread of this disease, which can have serious economic repercussions on poultry farming.

For more information, please see:

http://europa.eu/rapid/pressReleasesAction.do?refere nce $=I P / 11 / 1333 \&$ format $=H T M L$ \&aged $=0$ \&language $=E$ N\&guiLanguage $=$ en

http://ec.europa.eu/food/animal/diseases/ eradication/index_en.htm 